\title{
VENEREAL WARTS A CONTAGIOUS FORM OF TUMOUR.
}

\author{
By Charles W. Cathcart, F.R.C.S. (Eng. \& Ed.), Assistant Surgeon \\ in charge of Lock Wards, Royal Infirmary, Edinburgh.
}

THE diseases met with in the practice of lock wards are, from any point of view, unpleasant, but none, perhaps, better deserve the apt vulgar term of "dirty trouble," than aggravated cases of venereal warts. These growths do not cause actual pain to the patient, but the irritation produced by their discharge is considerable, and the smell to every one near is disgusting, while the genital organs, and sometimes the surrounding skin of the thighs and abdomen, become covered by a cauliflowery excrescence which disfigures the parts beyond recognition. Less advanced cases are of course proportionally less obnoxious, but in any degree the development of these growths is objectionable even to the unclean and degraded of either sex. Such warts are, moreover, fairly common; yet like many other objects which are neither beautiful nor rare, they have to the inquirer aspects of the deepest interest.

Among clinicians venereal warts are most frequently considered to be due to the irritation of gonorrhœal and other venereal discharges. Many think syphilis also to be capable of producing them. On the other hand, most pathologists, while accepting, either expressly or tacitly, this clinical account of their etiology, classify them among simple tumours, on the basis of their microscopic characters. To do so, however, is surely an anomaly, for new formations which are directly due to irritation should belong to the class of inflammations. Moreover, no external source of irritation has ever been traced as the direct cause of other simple tumours, such as a fatty or cartilaginous tumour, an adenoma of the mamma, or even of many of the other forms of papillomata with which the venereal warts are grouped.

A few quotations from standard authorities will show the present views on the subject.

In the tenth edition of Erichsen's "Science and Art of Surgery," 1895 , vol. ii., these warts are considered among men's diseases as local "sequences of gonorrhœa" (p. 1168). In the section on women's 
diseases it is said that "large condylomata or verruce are often met with here" (the labia) "as a result of syphilitic or gonorrhoeal disease."

In Treves "System of Surgery," 1895, vol. i., Mr. Jonathan Hutchinson, junior, who writes the article on gonorrhoea, includes warts among the "complications of gonorrhoa," and says: "In both sexes the growth of soft warts, sometimes to an extraordinary extent, is liable to result from the long-continued irritation of purulent discharge from the genitals, though there is no reason to think that they depend directly upon the gonococcus" (p. 439).

The same writer in another article, i.e. "Diseases of the Skin," says: "There is no doubt that local irritation, e.g. of some decomposing secretion, is the most frequent exciting cause in the formation of warts" (p. 707). And again, "Generally they owe their origin to an attack of gonorrhœa, but retained secretion (under a non-retracted prepuce) or the irritation of sexual intercourse may produce them." And again . . .

"Summary.-To recapitulate, the chief variety of warts met with may be grouped in the following manner:-

"1. Warts on the genital surfaces, due always to some local irritation (p. 710)."

2. In Walsham's "Theory and Practice of Surgery" 4th edition, 1892, among "Surgical Diseases of the Skin." the fourth group of papillomata is thus described:..... "Venereal warts met with on the genitals as the result of the irritation of gonorrhoal or other irritant discharges" (p. 345).

The view commonly held as to the relation of syphilis to warts is shown in the quotation just made from the article on "Diseases of Women " in "Erichsen's Surgery "; and to this I may add another, taken from Mr. J. Hutchinson, junior's, article on "Diseases of the Skin," to which I have already referred. Not long after the sentence quoted from p. 710, he goes on to say: "Secondary syphilis is also a common cause; thus a neglected condyloma may pass into the warty condition, and, apart from any mucous patch or condyloma, warts are liable to form on the dorsum of the tongue and elsewhere during the secondary stage" (p. 707-708); and in the summary already referred to, the second of the "chief varieties" is-

"Warty growths developing in old neglected condylomata, or otherwise depending on secondary syphilis for their origin" (p. 710).

It would be easy to multiply similar quotations from the clinical standpoint, if there were any advantage to be gained from so doing.

To illustrate the position taken up by pathologists we may refer to Hamilton's Pathology. He accepts the ordinary clinical view of the origin of venereal warts, when he says that "venereal warts grow from any part of the glans, or from the preputial mucosa, usually as a result of the stimulation of the part by the gonorrhoal poison" (1894, vol. ii. pt. 1, p. 384). They are, however, classed by 
him under "Tumours of Epi- and Hypoblastic Origin," and specified as "warts, horns, adenomas, cancers, etc." Further, "warts (verrucæ, papillomata)" are subdivided into four groups, of which the last are "condylomata and venereal warts" (1889, vol. i. p. 398).

Mr. Bland Sutton, in the article on "Tumours" in Treves' "System of Surgery," recognises four genera of epithelial tumours, namely, (1) papilloma, (2) epithelioma, (3) adenoma, (4) carcinoma. And four species of papillomata, namely, (1) warts, (2) villous papillomata, (3) intra-cystic warts, (4) psammomata. In speaking of warts he says: "They are often numerous on the glans penis, the anus, and labia, when these parts are irritated by purulent discharges, especially that of gonorrhoa" (vol. i. p. 476).

Mr. Jonathan Hutchinson, junior, to whose article on "Diseases of the Skin," we have already referred for a clinical opinion as to the etiology of venereal warts, says in another place: "It is practically impossible to draw any distinction between a wart and a papilloma, and the so-called papillomata of the larynx have a similar structure to many warts of the skin, allowing for slight differences due to their site" (p. 707).

Others, such as Coats, do not, indeed, discuss the etiology of soft or venereal warts, but place them among tumours. Thus: "Soft warts have distinctly the character of tumours presenting specialties of structure and growth, which entitle them to that designation " 1

It will probably be evident from these quotations that I have not overstated the discrepancy between the opinions held by clinicians and pathologists respectively as to the nature of venereal warts. For my own part, after a careful observation of many cases, and much consideration of the subject, I believe that venereal warts are directly contagious, and that the contagion is specific; that they are of the nature of tumours, properly so called, on account not only of their structure, but also of their clinical characters, and that local irritation, while it may stimulate their growth, does not cause it, unless in the obscure and remote sense in which it may be said that local irritation sometimes causes or at least originates epithelioma, and some other form of recognised tumour. What led me first to examine venereal warts with especial care was their apparent exception to what I had thought was a general rule. About four years ago I read before the Edinburgh Pathological Club a paper entitled, "Reasons for believing that Micro-Organisms will never be found to account for the Growth of Malignant Tumours." Among other arguments I pointed out that tumours are probably not irritative hypertrophies, because in many cases they present structures much more complex, varied, and complete than are found in the known hypertrophies (or hyperplasias) from irritation, while the simpler and more embryonic forms of tumour which seem to fit in with the irritation theory can be traced by successive

1 "Manual of Pathology," 3rd edition, London, 1895, p. 937. 
gradations into the more complex class for which irritation will not account. Venereal warts were, however, an apparent difficulty. They appeared too complex and definite in structure to be mere hypertrophies, and yet no one seemed to doubt their being due to local irritation. At first, too, the acknowledged tubercular origin of the so-called pathologist's wart seemed to strengthen the irritation view, and I began to wonder if, after all, irritation as a formative stimulus had not been underrated. About this time I was placed in charge of the Lock Wards, and before long a case of warty growths on the female genitals raised the question again and led me to observe this disease as closely as possible.

By degrees, as patients presented themselves for treatment at the Male Lock Ward, for warts which had cropped up soon after connection, but unaccompanied by gonorrhœe, I became more and more convinced of the independent existence of the two diseases, and I have now collected and arranged evidence on the subject which I trust will be as conclusive to others as it is to myself.

I propose, by an appeal to cases, to show reason for believing that warts are contagious, and that they are independent of local irritation, as well as of syphilis. I shall afterwards discuss their nature as tumours.

To the cases which have come under my own notice I am glad to be able to add those observed by others, partly because the series is thus made more complete, and partly because possible bias in $\mathrm{my}$ observations is thereby excluded.

\section{Venereal W WARTS ARE CONTAgious.}

A suspicion to this effect could hardly fail to arise in one's mind on seeing how often these growths follow shortly after impure connection, and yet are not associated, at least in my experience, with irritation due to other causes. This suspicion is strengthened as we see how the warts seem to spread themselves out from their original centre, and especially when we meet with cases in which external irritation is conspicuous by its absence, but it amounts almost to a conviction when we can obtain the evidence of confrontation. It is not, however, often possible to get this evidence in wart cases which are treated in a Lock Ward. The other person of either opposite sex is so difficult even to find, far less to examine, and the intercourse is often so frequent and so promiscuous. Hence, although I have on several occasions recently tried to follow up likely cases, I have for one reason or another been disappointed. I can present, however, two instances in which a husband has infected his wife with warts shortly after marriage, and I shall add a case of transmitted hard warts, which, although not venereal, may be taken along with the other two. 
CASE 1.-Numerous warts on the external genitals of a young woman shortly after marriage, previous warts on the glans penis and prepuce of the husband.-For this case and for permission to publish it I am indebted to the kindness of Dr. Allan Jamieson.

Some years ago Dr. Allan Jamieson was consulted by a recently married, thoroughly respectable young woman with the following history. Not long after marriage she had felt discomfort about the vulva. This had increased, and on examination a few weeks later Dr Jamieson found the labia covered with a luxuriant crop of warts. He interviewed her husband, and found that he had several warts on the glans penis and prepuce, which, he admitted, had been there when he was married. Neither husband nor wife had gonorrhœa.

CASE 2.-Gonorrhoea and warts in the vagina of a recently married young woman, previous gleet and a wart within the meatus of the husband. - This case came under my own observation when I was acting under Dr. P. H. Maclaren as non-resident clerk in the Lock Wards.

A respectable young woman was sent for treatment to the Female Lock Ward on account of vaginal disease which had developed a few months after marriage. On examination the whole of the mucous membrane of the vagina was found to be studded with thin pointed warts, and there was considerable discharge. Her husband came at the same time as an out-patient to the Male Lock Ward, and we found that he was suffering from a gleety discharge, and that he had a small wart in the urethral canal just within the meatus. These affections had existed before his marriage, but he had not considered them of any importance.

CASE 3.-Warts on the hand of a patient scraped off by medical attendant with his nail, followed shortly by growth of warts under that nail.-This case is published by Dr. Payne in the British Journal of Dermatology for 1891, p. 185 : "Charles B., æt. 11, healthy boy, out-patient in St. Thomas's Hospital, with a very copious eruption of warts. The right hand was nearly covered with them, chiefly the dorsal, but also the palmar surface. On the left hand they were rather less numerous. There were also a very large number of them on the face. The origin of the eruption was traced to a very large and horny wart on the palm of the right hand, which had existed more than 2 years. From this point the warts had spread over the right hand, then to the left, and had lately been extending very rapidly over the face. The total number must have been between two and three hundred. The boy was neat and cleanly for a child of his class, and his mother, a sensible, intelligent woman, gave a very clear history of the whole eruption. As the affection was very severe and disfiguring I took a good deal of pains in treating it locally, and after trying various means, of which salicylic acid collodion, and acetic acid were the most efficient, succeded in completely removing the trouble. When the warts were rendered soft and crumbling by the methods adopted I found the process was accelerated by scraping them away with the back or handle of a scalpel or similar instrument, and on one occasion thoughtlessly used my thumb nail to assist the operation. The result convinced me once for all of the contagiousness of warts. After a few days I noticed some redness and swelling under the thumb nail which had been thus used, and in about a week an unmistakable horny wart appeared on the spot. Afterwards a second and then a third wart appeared on the back of the same thumb. I abstained from treating these in order to watch their development, but in a few weeks they all spontaneously disappeared. Not having suffered from anything of the kind either then, or, as far as I can remember, in my life, I cannot doubt that these little troubles were due to some contagious matter lodged under the thumb nail, where it was not removed by the ordinary process of ablution." 
As confirmatory evidence of the communication of venereal warts by direct contagion, it is important to notice the spot to which many women point as that at which their warts first began. This is very often in the fold between the thigh and the labium majus, where the skin is thin, where warts on the penis are likely to be inoculated, and where the contagion is likely to remain undisturbed. Had local irritation from vaginal discharges been the cause, the warts would have been more likely to have shown themselves, first along the margins of the labia majora, or between the labia and the anus. These, indeed, are the common early seats of syphilitic condylomata, due apparently to local irritation acting along with the constitutional poison, but warts do not so often begin there. Another subsidiary piece of evidence pointing in the same direction, or at least against the irritation view, is the comparatively short interval of time which is often stated as having elapsed between the connection and the appearance of the warts. This will come out in some of the subsequent cases.

\section{Venereal Warts are Independent of Local IrRitation.}

This is a more difficult point to prove than that they are independent of gonorrhoea, but of course includes it. Most of the patients with venereal warts have gonorrhœa also; a fair number have no gonorrhœa, but only a few of these show entire freedom from discharge. Warts are themselves apt to excite a discharge by the intertrigo-like fermentation, which goes on in their interstices, and this may be confounded with a primary discharge to which their growth might have been attributed, unless simple wart cases are seen at an early stage. It is not surprising, therefore, that cases to prove this point are rare, but when found they are none the less valuable on that account as indicators of the truth. Nay more, from one point of view, their very rarity increases our confidence in the results to which they lead us, for it gives us a satisfactory explanation for the widespread belief in the older view. These exceptions must often have been observed and considered before, but they must have been either set aside or explained on some purely hypothetical basis, unless, indeed, they fell into the hands of those who were misled by the absurd popular fallacy that "an exception proves the rule" to be right, instead of recognising what the phrase really means, i.e., that the exception tests the rule and shows it to be imperfect or wrong.

CASE 4.-Warts on glans penis, no discharge.-James S., came from Methil, Fife, as an out-patient to the Male Lock Ward for advice. He stated that he had had intercourse several times within the last few months with a mill-girl, but with no one else, and that latterly these warts had begun to grow on his penis. He had a slight degree of hypospadias, so that the urethra opened on the under surface of the penis, about the usual position of the frænum, and the pre- 
puce showed the imperfect development which always accompanies this condition. There were 3 or 4 small warts close together on the dorsal side of the corona glandis, i.e. at the point furthest from the urethral opening. There was no gonorrhœa, nor discharge or sore of any kind about the penis, and he said there never had been. His general health was excellent.

The warts were situated on the part least likely to be affected by urethral irritation, had it existed. I wrote to the patient's medical attendant to see if the condition of the mill-girl could possibly be ascertained, and explained my reasons for wishing to know, but he did not favour me with a reply.

Case. 5. - Warts, no discharge of any kind.-Cameron P., out-patient Male Lock Ward, 26th April 1894, complained of penile warts which had been present for 9 months. They had appeared 3 weeks after connection. It was noted that he "had no discharge of any kind," and that the inguinal glands were enlarged on both sides. To the best of my recollection the patient said that he had not previously had discharge, but the note by the clerk does not involve this.

CASE 6.-Warts, no discharge, previous gonorrhoea without warts.-George M., came as an out-patient to the Male Lock Ward on 9th May 1895. He had had frequent intercourse from time to time, and several attacks of gonorrhoa. About 3 weeks after he had got rid of his last attack of gonorrhoea, he had connection again. Not long after this he felt discomfort under the prepuce, and soon the warts appeared for which he sought advice. He had a number of small warts on the prepuce and glans penis, but no urethral discharge, and no balanitis.

The special importance of this case is that gonorrhoa failed to cause warts to grow in a patient whose liability to their development was subsequently proved by their appearance after connection, but without apparent irritation.

CAsE 7.-Warts on the penis, without discharge, caused apparently by autoinoculation from warts at anus. - This case came under my notice when I was in charge of one of the general surgical wards during the holidays, about 4 years ago. A young man otherwise healthy was admitted on account of crops of warts on the glans penis, and near the anus. He had no gonorrhoea, nor other source of irritation on his penis. The history he gave was that he had not had connection, that he had first of all suffered from the warts at the anus, and that the warts on the penis had followed them. There was nothing in his condition to throw discredit on his statement, so he was treated in the general ward instead of being sent to the Lock Ward, as would otherwise have been done. I was so struck with the case that I had a coloured sketch made of the affected parts, and it might serve as a typical illustration of soft or venereal warts.

These four cases are all from men. The wart cases in women have mostly either been accompanied by gonorrhœa, or have been so well advanced before the patients applied for treatment, that warty discharge was present, hence for reasons already given I prefer to exclude them.

Although the exclusion of any form of irritation necessarily excludes gonorrhoa, there will be no harm in my adding a few cases where warts existed without gonorrhcea. In these there was a discharge, although I believe it was often secondary to the warts themselves, and we are now in a better position to accept this view of it. Many of these cases are interesting as bringing out the incubation period of the wart contagion, if for nothing else. 


\section{Venereal Warts are Independent of Gonorrhoa.}

CASE 8. - Extensive development of warts on the vulva, no gonorrhoea or other vaginal discharge.-This patient, C. B., a previously respectable girl from a town in Fife, asserted that she had been seduced by her sweetheart. On her admission to the Female Lock Ward, a very extensive growth of warts which had followed her seduction completely covered her labia on both sides. There was considerable foul smelling discharge from the warts. Under chloroform the warts were clipped away with scissors, and during the operation I examined the vagina, and was struck by its entire freedom from discharge. She made a good and quick recovery, and had no vaginal discharge from first to last. There was a history of her hair having fallen out, to a slight extent, before she came to Edinburgh, and she had a few suspicious spots on the skin. She, therefore, may also have had syphilis.

CASE 9.-Warts on penis a fortnight after connection, no gonorrhoea.$J$. M'J sought advice as an out-patient in the Male Lock Ward on 22nd March 1894. He said that he had had connection "at the New Year"; soon afterwards his penis became painful but without any sore, and a fortnight after connection he noticed the warts beginning to grow. He had a crop of warts all round the corona, especially on the left side, also at the margin of the prepuce, but no gonorrhœea. There was, I think, "wart" discharge in this case.

$\mathrm{C}_{\mathrm{ASE}}$ 10.-Warts and discharge from beneath foreskin, no gonorrhoca.James W., æt. 26, came as an out-patient to the Male Lock Ward on 14th May 1895, with the following history:-At the New Year he had had connection; 2 weeks afterwards he had noticed matter coming from beneath his foreskin, but as the orifice of the prepuce was tight, he could not ascertain the cause of the discharge; 2 weeks afterwards, however, he was able to see warts growing within the prepuce. He was treated as an out-patient at first, and at a subsequent visit on 10th June, it was noted that the warts had increased in size, but that there was no gonorrhoal discharge. He was afterwards admitted and circumcised.

Case 11.-Warts, no gonorrhoea.-In the British Medical Journal for 25th May 1895, among the queries there was the following: L.R.C.P. writes: "Will some member kindly give me a hint as to how to rid a patient of warts round the corona glandis and on the glans penis? He has not had gonorrhcea, but the warts appeared some short while after connection?" Through the editor I was put in communication with the inquirer, and gave him all the advice I could on the subject. In return I asked him to let me have a few particulars of the case to help me in my present inquiry, but my letter was not even acknowledged.

CASE 12.-Warts round anus, extending within sphincter, no illicit intercourse.-John R., æt. 29, married; was admitted to the Male Lock Ward in May 1895, to have warts round and within anus removed. He denied having had intercourse, except with his wife, and had no sign or history of venereal disease of any kind. He said that for the last 12 years he had been aware of three small "tumours" (warts) near his anus. They had remained unchanged until the beginning of the year, when they had begun to grow and multiply without apparent cause. The skin round the anus was quite covered with warts resembling those seen in venereal cases when, as often occurs in women, the warts spread from the genital organs to the anal region. When the patient was anæsthetised for the removal of the warts, I found that they had spread up the anal canal, and it was necessary to stretch the sphincter 
thoroughly before I could reach them. They must have extended quite to the top of the anal canal, i.e., that formerly known as the third part of the rectum.

It will not, I think, be necessary to multiply these cases, although my list includes several more.

\section{VEnereal Warts ARE INDEPENDENT OF SYPhILIS.}

That this is the case there seems little room for doubt, when we consider that, except in the case of C. B., No. 8, there was no reason to believe that syphilis was present in any of the cases I have quoted. Still there must be some ground for the view held by many good authorities that the two diseases are associated. We can indeed never quite get rid of an erroneous view till we have exposed and explained the basis for its previous existence. It is therefore well to consider at least two plausible grounds for the existing view. One is that syphilis and warts are often present in the same patient, and the other and more subtle reason is that in some patients secondary syphilis actually causes a warty form of growth, which might easily be mistaken for warts, although it is essentially different.

Syphilis is a rarer disease than gonorrhœe, and warts are probably rarer than either; hence it is only natural to expect, what we actually find, that warts are less frequently associated with syphilis than they are with gonorrhœa, and still less frequently occur by themselves. So far indeed as the argument from mere association of the diseases is concerned, the cases already quoted ought to suffice for clearing syphilis, as much as gonorrhoea or other local source of irritation, from the imputation of causing warts.

As to the warty developments in secondary syphilis, however, a few more words will be necessary. Much confusion has been caused by the double use of the word condyloma, i.e. condyloma acuminatum, as indicating a wart, and condyloma latum, as indicating a condition found in secondary syphilis. The ordinary form of condylomatous eruption is quite easily distinguished from warts, and it would be much better to restrict the word condyloma entirely to the syphilitic condition. This double use of the word must have been a source of confusion to those whose clinical experience has been limited, but I will not now dwell on it. The more subtle source of confusion to which I have referred is something different, and is this. In a limited number of patients suffering from secondary syphilis only, the condyloma is warty. This development seems to take place in a limited number of patients of either sex, and especially when the skin near the anus is affected. In some cases the warty excrescence may be considerable, but it has the following features by which it may be distinguished: -The separate processes, sometimes $\frac{1}{4}$ in. in length, may be as 
delicate as those of large warts, but they are then not isolated, but subdivisions, as it were, of a larger mass. Isolated patches in such patients, even when as large as a threepenny-piece, are undivided, although they may have a perceptible pedicle. Again, the larger masses of warty, condylomatous processes are like the smaller individual growths in this, that the general surface is so level that it looks as if it had been planed. Warts, on the other hand, when in masses, are more irregular on the surface, and individually show more distinctly branching processes, and are more clearly pedunculated. By these features one can often recognise the two kinds of growth on the same patient, and it is interesting to trace a further proof of their difference in their different behaviour under treatment. Under mercury internally, cleanliness and application of drying powders locally, the syphilitic warty growth gradually subsides, and finally sinks down into the level of the surrounding skin. The warts, in my experience, are very seldom affected at all by this treatment, and may even increase and multiply under it, and even when they do not grow they become more conspicuous as the others become less. In the few cases where I have seen them affected by mere cleanliness and drying, they disappear by shrivelling and dropping off like dead leaves-not by becoming reabsorbed from within.

The difference I believe to be due to an essential difference in the mode of growth-the condyloma seems to be due to an overgrowth of the connective tissue (probably irritative), to which the epithelial covering is secondary, while the wart seems to be essentially an epithelial new growth, of which the connective tissue is a subsidiary part. Why some patients should show this warty form of condyloma, I cannot say. Its liability to be warty round the anus may possibly be due to the structure of the skin at this place-permitting, as it does, physiological dilatation at defecation.

\section{Venereal Warts are of the Nature of Tumours.}

We pass now from the region of observation to that of deduction, although I trust that the ground for it has been sufficiently well laid.

I hope that I have been able to establish that venereal warts are contagious. It might have been said that this was due to their depending on a contagious form of irritation, were it not that the following arguments, deduced partly from the foregoing cases, can now be set against that view. (1) Venereal warts may exist on the genitals, apart from any evident source of irritation, present or past; hence, although such warts and venereal discharges are more often associated than not, the association is accidental, not that of cause and effect. This is, to my mind, the most important argument; the following are, however, interesting confirmations of it:-(2) Venereal warts having begun on the skin, where they might have been considered hyper- 
trophies of the papillæ, can spread to the urethral mucous membrane and anal canal, where there are no normal papillæ from which they could have sprung. On these situations they have a similar relation to the original epithelium that warts of the larynx have, except that the latter arise there as tumours from the first. (3) Local irritation by discharges, on parts of the body where wart contagion is absent, may continue for almost indefinite periods without causing warts, as in many forms of skin disease and in discharging sinuses. (4) Warts can be traced as following illicit intercourse within a few weeks, thus not giving time for the "long-continued irritation" which is believed to be necessary by the advocates of this view. (5) The overgrown papillæ in elephantiasis, and the warty and tuberculated appearance of the skin sometimes seen near urinary fistulæ or callous ulcers, are quite distinguishable from the growth of true warts.

If, then, warts are contagious, and are not due to irritation, a specific contagion seems the only alternative. What is it? Some will say, an organism not yet identified which lives in the epithelial cell, and stimulates it to multiply and arrange the new cells into a branching wart. A more probable view, in my opinion, is that we are dealing here, not, as the pathologists suppose, with an ordinary simple tumour, but one with contagious properties. No one, so far as I know, thinks a hypothetical organism necessary for the growth of a fatty tumour, or a mammary adenoid, neither does such a stimulus seem required for a venereal wart. It is, moreover, well known that simple tumours arise without any apparent cause. So warts about the genital organs or anus may also arise in this same mysterious way, although their remarkable contagious property accounts most frequently for their presence on these parts. If, however, we are agreed that venereal warts are genuine tumours, it is highly interesting to note that they have characters which seem to link them with malignant tumours on the one hand, and with simple tumours on the other. Thus they resemble malignant tumours in their occasional great rapidity of growth, in their power of producing secondary growths on the same individual, and to a less extent in their power of contagion also, for there seem to be a few authentic cases of epithelioma transmitted from the cervix uteri to the penis. But they are still essentially simple tumours in their inability to invade or infiltrate the deeper tissues, and, in what probably follows from it, their apparent inability to be transmitted by blood or lymph stream, and in the comparative ease with which they may be destroyed.

This peculiar combination of characters, however, is not difficult to accept, when we remember that many other groups of tumours have individual characters in their mode of spreading, rates and modes of growth, and in other particulars.

Some at least of the life characters of these other tumour groups can be explained, either as varieties of an admitted irregularity in the 
law of growth, or as an inherited resemblance to the characters of the original tissue from which the tumour sprang. Variations in rate of growth are among the former, and of the latter I will give one, but only one, illustration. It occurred to me when I was studying tumours of bone. It is generally true among non-epithelial tumours, at least, that those which are cellular in structure all through, and which grow rapidly, are malignant in proportion as these features are prominent. This is because "cellular" is generally synonymous with " embryonic." Myeloid tumours of the bones, however, often grow very rapidly, and are entirely cellular, and yet in many cases do not cause secondary deposits, and can be eradicated without very sweeping measures. A satisfactory explanation of this is, that they take their origin from the medulla whose adult stage is cellular, and that either developing red blood corpuscles or hæmorrhage from delicate vessels probably forms a considerable part of their bulk, so that their rapid increase can thus also be easily explained.

Let us see if what we know of skin epithelium and the circumstances of these warts will in like manner explain some of their peculiar characters.

There is, perhaps, no tissue more easily transplanted from different parts of the same person, or from one person or animal to another, than epithelium. No tumour of the deeper textures could have such opportunities for showing its transmissibility by contact, if it possessed it, than a tumour of the skin has, and no part of the skin could be more suitable for the purpose, if I may put it so, than that covering the external genital organs, especially in the class of persons among whom this disease is most common. The auto-inoculable and contagious characters of these warty tumours are, from this point of view, therefore, quite intelligible.

Again, epithelium is a tissue which physiologically is rapidly reproduced. Thus tumours composed mainly of this tissue might increase rapidly, and yet not deviate greatly from their adult condition-hence warts may easily be simple, although sometimes rapidly growing. They do not always grow fast, but they may have the power without always exerting it.

The last point which I wish now to remark upon is the circumstances necessary for their propagation. From the way in which they can be seen sprouting up all round the main mass, it seems certain than an actual abrasion of surface is not necessary. On the other hand, they do not seem to spread easily on firm dry skin. Where they extend most rapidly the skin is kept moist and vascular from the irritation of the discharge which comes from the growing warts. This discharge probably contains countless growing cells from the surface of the warts, and these cells must find a suitable nidus among the partially exposed epithelial cells of the adjacent skin or mucous membrane.

I am willing to admit that I have twice unsuccessfully tried to plant 
warts on a new place, when I was removing them, but it was on to a raw surface, which was probably a mistake, and one or two negative results do not count for much against the evidences for auto-inoculation and contagion which are to be found in clinical experience.

Although I have kept almost entirely to venereal warts in this paper, I have no reason to doubt that the common spreading hand warts are essentially similar, and I am prepared to find that they may be spread from the hands to the genital organs, although I have not as yet met with such a case.

The views which I now offer for acceptance seem not only to fit in with clinical facts better than the views held heretofore, but they also, I venture to think, throw some side-light on the very interesting subject of tumour pathology. 